\title{
Comparative study of combined vitrectomy with phacoemulsification versus vitrectomy alone for primary full-thickness macular hole repair
}

\author{
Christophe Valmaggia ${ }^{* *}$, Filip Kostadinov ${ }^{2}$, Corina Lang ${ }^{1}$ and Josef Guber ${ }^{1}$
}

\begin{abstract}
Background: To assess the effectiveness and safety of 23-gauge pars plana vitrectomy combined with phacoemulsification versus vitrectomy alone in patients over 50 years with primary full-thickness macular holes (FTMH).

Methods: We retrospectively reviewed the medical records related to 406 consecutive vitrectomies performed for primary FTMH. Phacovitrectomy was performed in 294 phakic eyes whereas vitrectomy alone in 112 pseudophakic eyes. The cases were divided into three groups according to the stage of the FTMH: stage $2(n=93)$, stage $3(n=$ $270)$, or stage $4(n=43)$. The primary outcome measure was the closure of the FTMH. The secondary outcome measures were the evolution of visual acuity as well as intraoperative and postoperative complications.
\end{abstract}

Results: Neither the primary nor the secondary outcomes differed between phacovitrectomy and vitrectomy alone for all three stages. The FTMH were closed in 375 eyes $(92.4 \%)$ after a first operation. The closure rate was higher for stage $2(96.8 \%)$ than for stages $3(91.1 \%)$ or $4(90.75 \%)$, but not significantly ( $P=0.189)$. The mean visual acuity increased significantly from preoperatively LogMAR $0.68( \pm$ SD 0.2) to LogMAR $0.43( \pm$ SD 0.24$)$ at the end of the follow-up $(p<0.001)$.

Conclusions: Combined 23-gauge pars plana vitrectomy with phacoemulsification for primary FTMH repair in patients over 50 years is as efficient and safe when compared with vitrectomy only.

Trial registration: The study was approved on $30^{\text {th }}$ April 2020 by the local ethics committee (Ethikkommission Ostschweiz, EKOS 20/074; BASEC Nr. 2020-01033).

Keywords: Macular hole, Pars plana vitrectomy, Phacoemulsification, Phacovitrectomy

\section{Background}

Full-thickness macular hole (FTMH) is defined as a foveal lesion with interruption of all retinal layers from the internal limiting membrane to the retinal pigment epithelium [1]. Tangential or perpendicular traction to

\footnotetext{
* Correspondence: christophe.valmaggia@kssg.ch

'Department of Ophthalmology, Cantonal Hospital St. Gallen, Rorschacher Strasse 95, 9007 St. Gallen, Switzerland

Full list of author information is available at the end of the article
}

the vitreoretinal interface plays an important role in the development of primary FTMH. If the posterior vitreous detachment is incomplete, epiretinal cell proliferation and fibrosis are essential parts of the pathogenesis too [2]. Secondary FTMH is related to other pathologic features such as high myopia, macular schisis, macular telangiectasia, wet age-related macular degeneration, surgical or ocular trauma without any preexisting or concurrent vitreomacular traction $[1,3]$. Primary FTMH

C C The Author(s). 2021 Open Access This article is licensed under a Creative Commons Attribution 4.0 International License, which permits use, sharing, adaptation, distribution and reproduction in any medium or format, as long as you give appropriate credit to the original author(s) and the source, provide a link to the Creative Commons licence, and indicate if changes were made. The images or other third party material in this article are included in the article's Creative Commons licence, unless indicated otherwise in a credit line to the material. If material is not included in the article's Creative Commons licence and your intended use is not permitted by statutory regulation or exceeds the permitted use, you will need to obtain permission directly from the copyright holder. To view a copy of this licence, visit http://creativecommons.org/licenses/by/4.0/. The Creative Commons Public Domain Dedication waiver (http://creativecommons.org/publicdomain/zero/1.0/) applies to the data made available in this article, unless otherwise stated in a credit line to the data. 
is diagnosed in 86 to $92 \%$ of cases [4]. The reported prevalence is $0.02-0.8 \%$, with 7.8 new cases per $100^{\prime} 000$ population per year [5]. The peak incidence is thought to be in the seventh decade of life [5]. The male-tofemale ratio is $1: 2$ to $1: 3.3$ [5]. The female predominance in primary FTMH is explained by the postmenopausal drop in the estrogen levels, leading to increased vitreous liquefaction, and thus a higher likelihood for FTMH [6].

The success of surgery in the treatment of primary FTMH has been reported in several studies [7]. The failure rate of primary surgery is less than $10 \%$ but the nonclosure rate for large FTMH may be as high as $44 \%$ $[8,9]$. Nevertheless, the optimal treatment for patients with both vitreoretinal and cataract disease is still a matter of debate [10-12]. A combined surgery, hereafter called phacovitrectomy, or a sequential surgery with a vitrectomy followed by a cataract operation both have their pros and cons [13, 14]. Meanwhile, phacovitrectomy is an accepted approach. However, more postoperative refractive prediction errors as well as increased post-operative inflammatory response in patients undergoing phacovitrectomy are reported $[15,16]$. To date, recent studies on phacovitrectomy have mostly reviewed inhomogeneous groups of patients with diverse vitreoretinal pathologies, which makes interpretation difficult [17-20]. The present study was designed specifically to assess the effectiveness and safety of a 23-gauge pars plana vitrectomy for primary FTMH repair in patients over 50 years [21]. A group of patients treated by phacovitrectomy is compared with a group of already pseudophakic patients treated only by vitrectomy. This model allows a direct comparison between phacovitrectomy and vitrectomy alone for a well-defined pathology, avoiding the need to take into account possible complications related to a subsequent cataract operation in the control group.

\section{Materials and Methods Subjects}

In this retrospective study, the medical history of all consecutive patients over 50 years of age treated exclusively for primary FTMH at the Cantonal Hospital St. Gallen, Switzerland between January 2010 and December 2019 were reviewed. Patients with secondary FTMH were excluded from the study, namely: high myopia, macular schisis, macular telangiectasia, wet age-related macular degeneration, previous pars plana vitrectomy (e.g. for vitreomacular pathologies or retinal detachment), and blunt trauma [1,3].

The classification of the FTMH was made using optical coherence tomography (OCT) images (Spectralis, Heidelberg, Germany). The staging was defined according to the modified Gass classification system: stage 2 for macular holes of $\leq 400 \mu \mathrm{m}$, stage 3 for macular holes of $>400 \mu \mathrm{m}$ with an attached vitreous body, and stage 4 for macular holes of $>400 \mu \mathrm{m}$ with posterior vitreous body detachment [22]. The aperture size of the FTMH was measured at the narrowest hole width using the caliper function of the OCT device as a line drawn approximately parallel to the retinal pigment epithelium [23]. The primary outcome measure was the OCT-confirmed closure of the FTMH defined as a flattened and reattached hole rim along the whole circumference of macular hole without exposed retinal pigment epithelium [23]. The secondary outcome measures were the evolution of the best-corrected visual acuity (BCVA), the intraoperative complications (e.g. posterior capsule rupture, retinal tears, vitreous or retinal bleeding), and the postoperative complications (e.g. lens subluxation, iris capture, endophthalmitis, perfusion disorder, retinal or choroidal detachment, intraocular pressure (IOP) decompensation, macular edema). The BCVA was recorded as a Snellen visual acuity and converted to the logarithm of the minimum angle of resolution (LogMAR) for statistical analysis. For the entire data considered, the end of the follow-up coincided with the last entries in the medical history.

\section{Surgical procedure}

The surgeries were performed under general anesthesia by three senior surgeons (C.V., C.L., and J.G.). A standard pars plana vitrectomy with three 23 gauge-valved ports (Stellaris System, Bausch \& Lomb, USA), and a wide-angle viewing system (Oculus BIOM 5, Germany) was performed. A posterior vitreous body detachment was induced if not present, and a core and peripheral vitrectomy was done with scleral indentation. The internal limiting membrane and, if present, the epiretinal membrane were stained (MembraneBlue-Dual DORC, The Netherlands), and removed from the macular area with an end-gripping micro forceps. A search for retinal tears was performed with scleral indentation. Any breaks or suspicious areas were treated either with cryotherapy or argon laser retinopexy. At the end of the surgery, fluidgas exchange was performed and $20 \%$ sulfur hexafluoride was applied as intraocular tamponade. All three sclerotomies were closed with a synthetic, absorbable suture (Vicryl Rapid 8.0, Ethicon, USA). For the phacovitrectomy, the three 23 gauge-valved ports were placed before performing the cataract surgery. Phacoemulsification was carried out through a $2.6 \mathrm{~mm}$ sclerocorneal tunnel incision. The capsulorhexis of the anterior capsule was made with its margin covering the edge of a 6.0-mm optic intraocular lens. The residual cortex was removed using irrigation/aspiration cannulas. A foldable one-piece hydrophobic acrylic intraocular lens was implanted in the capsular bag using a preloaded injector system. The postoperative treatment regime consisted of 
the topical application of tobramycin $(0.3 \%)$ and dexamethasone $(0.1 \%)$ three times a day for three weeks. No routine anti-ocular hypertensive medication was given. Patients were advised to posture face-down eight hours for three days.

\section{Statistical analysis}

The categorical variables were compared using a ChiSquare test with Yate correction. For the continuous variables, a One-Way Analysis of Variance test was used for between-group comparisons and a two-tailed paired sample t-Test for within-group comparisons. Logistic regression assessed the correlations between various predictors such as gender, age, stage of the FTMH or preoperative BCVA and the postoperative macular hole closure. A $P$-value $<0.05$ was considered statistically significant. The sample size of the study allowed the detection of a LogMAR change of \pm 0.1 with a power greater than $90 \%$, considering a LogMAR standard deviation of 0.2 for the preoperative BCVA and a type-I error $\alpha=$ $5 \%$. All analyses were carried out with the Social Science Statistics (Version 2020).

\section{Results}

A total of 406 eyes were included in the study. A number of 376 patients (234 women, 142 men) were treated monocularly, and 15 patients ( 11 women, 4 men) bilaterally. The data of the patients treated with phacovitrectomy or vitrectomy alone for macular holes stage 2, 3, and 4 are reported in Table 1 . The evolutions of the BCVA and the IOP are given in Table 2 respectively in Table 3.

The groups of phacovitrectomy and vitrectomy alone were matched for the following preoperative patients' characteristics: gender, laterality, mean preoperative BCVA, and mean preoperative IOP. The patients with pseudophakic eyes were older in the vitrectomy alone group which was significant for the women with stages 2 , or 3 macular holes $(P<0.001)$, and for the men with stage 3 macular holes $(P=0.007)$.

As for the primary outcome measure, the FTMH were closed in 375 eyes $(92.4 \%)$ after a first operation. The closure rate was higher for stage $2(96.8 \%)$ than for stages $3(91.1 \%)$ or $4(90.75 \%)$, but not significantly $(P=0.189)$. For the three stages, the closure rate did not differ significantly if a phacovitrectomy or a vitrectomy alone was performed. Better preoperative BCVA was significantly associated with a higher occlusion rate $(p=$ $0.010)$, while the predictors gender $(p=0.94)$ and age $(p=0.75)$ were not.

As for the secondary outcome measures, the mean BCVA statistically improved from LogMAR $0.68( \pm$ SD $0.2)$ to $\operatorname{LogMAR} 0.43( \pm \mathrm{SD} 0.24)$ at the end of the follow-up $(P<0.001)$. The mean IOP decreased from $14.83 \mathrm{mmHg}( \pm$ SD 2.92$)$ to $12.87 \mathrm{mmHg}( \pm$ SD 4.01) at the first postoperative day $(P<0.001)$, and increased to $16.21 \mathrm{mmHg}( \pm \mathrm{SD} 4.02)$ at the end of the follow-up $(P<0.001)$. The outcomes related to the evolution of BCVA and the IOP did not differ significantly between the groups of patients treated with phacovitrectomy or vitrectomy alone. An intraoperative retinopexy was performed in 135 eyes (33.3\%). This rate was indeed higher for stages $2(32.5 \%)$ and $3(35.9 \%)$ compared with stage 4 (18.6\%), but not significantly $(P=0.079)$.

The following postoperative complications were treated medically with success: six cases of ocular hypertension after phacovitrectomy ( $2 \%)$, and four cases after vitrectomy alone (3.6\%); one case of OCT- confirmed macular edema three weeks after phacovitrectomy $(0.3 \%)$. The following postoperative complications were treated surgically: one case of iris capture after phacovitrectomy $(0.3 \%)$; two cases of lens subluxation after vitrectomy alone $(1.8 \%)$; one case of retinal detachment

Table 1 Data of the patients treated with phacovitrectomy or vitrectomy alone for macular holes

\begin{tabular}{|c|c|c|c|c|c|c|c|c|c|}
\hline & \multicolumn{3}{|c|}{ Macular holes stage 2} & \multicolumn{3}{|c|}{ Macular holes stage 3} & \multicolumn{3}{|c|}{ Macular holes stage 4} \\
\hline & Phako-PPV & PPV & $P$ Value & Phako-PPV & PPV & $P$ Value & Phako-PPV & PPV & $P$ Value \\
\hline Number of eyes $(n)$ & 72 & 21 & & 197 & 73 & & 25 & 18 & \\
\hline Women / men (n) & $52 / 20$ & $13 / 8$ & $0.524^{*}$ & $127 / 70$ & $39 / 34$ & $0.129^{*}$ & $14 / 11$ & $11 / 7$ & $0.982^{*}$ \\
\hline $\begin{array}{l}\text { Mean age in years for women } \\
( \pm S D)\end{array}$ & $\begin{array}{l}68.06 \\
( \pm 5.22)\end{array}$ & $\begin{array}{l}75.46 \\
( \pm 6.19)\end{array}$ & $<0.001 \dagger$ & $66.12( \pm 6.84)$ & $75.42( \pm 8.31)$ & $<0.001 \dagger$ & $69.14( \pm 7.79)$ & $72.64( \pm 4.24)$ & $0.195+$ \\
\hline $\begin{array}{l}\text { Mean age in years for men } \\
( \pm S D)\end{array}$ & $\begin{array}{l}68.50 \\
( \pm 7.57)\end{array}$ & $\begin{array}{l}71.87 \\
( \pm 6.66)\end{array}$ & $0.281+$ & $69.17( \pm 6.93)$ & $75.03( \pm 6.18)$ & $0.007+$ & $66.45( \pm 13.74)$ & $72.43( \pm 7.39)$ & $0.309+$ \\
\hline Right eye / left eye (n) & $40 / 32$ & $8 / 13$ & $0.248^{*}$ & $97 / 100$ & $31 / 42$ & $0.393^{*}$ & $11 / 14$ & $9 / 9$ & $0.937^{*}$ \\
\hline Mean follow-up in days $( \pm S D)$ & $\begin{array}{l}16.23 \\
( \pm 6.06)\end{array}$ & $\begin{array}{l}14.33 \\
( \pm 4.23)\end{array}$ & $0.186+$ & $16.70( \pm 11.59)$ & $17.88( \pm 12.51)$ & $0.472 \dagger$ & $19.6( \pm 10.05)$ & $20.44( \pm 9.83)$ & $0.785 \dagger$ \\
\hline Macula hole closed / open (n) & $71 / 1$ & $19 / 2$ & $0.248^{*}$ & $184 / 13$ & $62 / 11$ & $0.053^{*}$ & $24 / 1$ & $15 / 3$ & $0.379^{*}$ \\
\hline Retinopexy / no retinopexy (n) & $24 / 48$ & $6 / 15$ & $0.884^{*}$ & $77 / 120$ & $20 / 53$ & $0.102^{*}$ & $5 / 20$ & $3 / 15$ & $0.904^{*}$ \\
\hline
\end{tabular}

* Chi-Square test with Yate correction; † One-Way Anova for between-group comparisons; PPV Pars plana vitrectomy, SD Standard deviation. 
Table 2 Evolution of the best corrected visual acuity for the patients treated with phacovitrectomy or vitrectomy alone for macular holes

\begin{tabular}{|c|c|c|c|c|c|c|c|c|c|}
\hline & \multicolumn{3}{|c|}{ Macular holes stage 2} & \multicolumn{3}{|c|}{ Macular holes stage 3} & \multicolumn{3}{|c|}{ Macular holes stage 4} \\
\hline & $\begin{array}{l}\text { Phako- } \\
\text { PPV }\end{array}$ & PPV & $P$ Value & $\begin{array}{l}\text { Phako- } \\
\text { PPV }\end{array}$ & PPV & $P$ Value & Phako-PPV & PPV & $P$ Value \\
\hline $\begin{array}{l}\text { Mean BCVA preoperatively in LogMAR } \\
( \pm \text { SD })\end{array}$ & $\begin{array}{l}0.60 \\
( \pm 0.28)\end{array}$ & $\begin{array}{l}0.59 \\
( \pm 0.20)\end{array}$ & $0.918+$ & $\begin{array}{l}0.69 \\
( \pm 0.28)\end{array}$ & $\begin{array}{l}0.76 \\
( \pm 0.26)\end{array}$ & $0.132+$ & $0.95( \pm 0.47)$ & $0.90( \pm 0.30)$ & $0.800+$ \\
\hline $\begin{array}{l}\text { Mean BCVA end of follow-up in LogMAR } \\
( \pm \text { SD) }\end{array}$ & $\begin{array}{l}0.39 \\
( \pm 0.22)\end{array}$ & $\begin{array}{l}0.31 \\
( \pm 0.19)\end{array}$ & $0.340+$ & $\begin{array}{l}0.46 \\
( \pm 0.22)\end{array}$ & $\begin{array}{l}0.51 \\
( \pm 0.33)\end{array}$ & $0.435+$ & $0.45( \pm 0.17)$ & $0.49( \pm 0.16)$ & $0.597 \dagger$ \\
\hline $\begin{array}{l}\text { P Value: BCVA preoperatively vs. end of } \\
\text { follow-up }\end{array}$ & $<0.001 \neq$ & $0.003 \neq$ & & $<0.001 \neq$ & $<0.001 \neq$ & & $0.002 \neq$ & $0.002 \ddagger$ & \\
\hline
\end{tabular}

† One-Way Anova for between-group comparisons; ₹ two tailed paired sample t-Testfor within-group comparisons. BCVA Best corrected visual acuity, LogMAR Logarithm of the minimum angle of resolution, PPV Pars plana vitrectomy, SD Standard deviation.

seven months after vitrectomy alone $(0.9 \%)$. Two cases of transient vitreous bleeding each after phacovitrectomy $(0.7 \%)$ and vitrectomy alone $(1.8 \%)$ were observed; they all resolved spontaneously within three weeks showing no increase in IOP; they presumably arose from the sclerotomies, since other perioperative pathologies were excluded. No treatment was possible in one case of partial vein occlusion diagnosed at the first postoperative day after phacovitrectomy $(0.7 \%)$ which resulted in irreversible worsening of BCVA. Specifically, no serious inflammatory reactions had been observed.

\section{Conclusions}

Despite the successful treatment of FTMH with vitrectomy, postoperative cataract formation remains an inevitable consequence whose mechanism is not completely understood. The protective role of the vitreous body was supported in clinical studies as transconjunctival small gauge nonvitrecromizing vitreous surgery for epiretinal membrane induced less progression of cataract compared with conventional small gauge vitrectomy [24, 25]. In the absence of the vitreous gel, molecular oxygen from the retinal vasculature may possibly reach the lens easier and then promote oxidative damage of the lens nucleus, an increase in light scattering, and nuclear sclerotic cataract [26]. Cataract develops at a median of about eight months after vitrectomy, and this delay is reduced to about four months median value if the lens is damaged during the vitrectomy [27]. Usually, the majority of the patients require a cataract surgery within two years of vitrectomy [28]. Moreover, a cataract operation in an already vitrectomized eye is challenging due to lack of support of the vitreous body, the instability of the anterior chamber, and the possible development of a miosis during the procedure [29]. Therefore combined phacovitrectomy has gained popularity. A phacovitrectomy firstly enables patients to improve their visual acuity after a single operation without any deterioration due to cataract progression [30], secondly the surgeons to perform the cataract operation under normal conditions and avoid the difficulties that this operation entails for an eye that has already been vitrectomized [31], and thirdly the healthcare system to reduce the costs and burden of sequential surgery [32].

In the present study, the primary endpoint, macular hole closure and the secondary endpoints, the development of BCVA and intraoperative and postoperative complications, were similar in both procedures, the phacovitrectomy and vitrectomy alone for macular holes of stages 2,3 , and 4 . The rate of macular hole closure was

Table 3 Evolution of the intraocular pressure for the patients treated with phacovitrectomy or vitrectomy alone for macular holes

\begin{tabular}{|c|c|c|c|c|c|c|c|c|c|}
\hline & \multicolumn{3}{|c|}{ Macular holes stage 2} & \multicolumn{3}{|c|}{ Macular holes stage 3} & \multicolumn{3}{|c|}{ Macular holes stage 4} \\
\hline & $\begin{array}{l}\text { Phako- } \\
\text { PPV }\end{array}$ & PPV & $P$ Value & Phako-PPV & PPV & $P$ Value & Phako-PPV & PPV & $P$ Value \\
\hline Mean IOP preoperatively in $\mathrm{mmHg}( \pm \mathrm{SD})$ & $\begin{array}{l}14.64 \\
( \pm 2.84)\end{array}$ & $\begin{array}{l}13.71 \\
( \pm 2.49)\end{array}$ & $0.181 \dagger$ & $\begin{array}{l}15.13 \\
( \pm 2.92)\end{array}$ & $\begin{array}{l}14.85 \\
( \pm 3.12)\end{array}$ & $0.488+$ & $14.40( \pm 2.47)$ & $14.11( \pm 3.31)$ & $0.744 \dagger$ \\
\hline $\begin{array}{l}\text { Mean IOP first postoperative day in } \mathrm{mmHg} \\
( \pm \mathrm{SD})\end{array}$ & $\begin{array}{l}12.72 \\
( \pm 4.06)\end{array}$ & $\begin{array}{l}12.52 \\
( \pm 5.47)\end{array}$ & $0.856+$ & $\begin{array}{l}12.95 \\
( \pm 3.80)\end{array}$ & $\begin{array}{l}13.19 \\
( \pm 3.51)\end{array}$ & $0.640+$ & $12.40( \pm 4.17)$ & $12.44( \pm 5.93)$ & $0.977+$ \\
\hline $\begin{array}{l}P \text { Value: IOP preoperatively vs. first } \\
\text { postoperative day }\end{array}$ & $0.002 \ddagger$ & $0.330 \neq$ & & $<0.001 \neq$ & $0.001 \neq$ & & $0.014 \neq$ & $0.236 \neq$ & \\
\hline Mean IOP end of follow-up in mmHg ( \pm SD) & $\begin{array}{l}15.99 \\
( \pm 4.77)\end{array}$ & $\begin{array}{l}18.24 \\
( \pm 5.78)\end{array}$ & $0.073+$ & $\begin{array}{l}16.07 \\
( \pm 4.28)\end{array}$ & $\begin{array}{l}16.49 \\
( \pm 3.43)\end{array}$ & $0.459+$ & $16.36( \pm 2.83)$ & $14.89( \pm 2.54)$ & $0.087 \dagger$ \\
\hline $\begin{array}{l}P \text { Value: IOP preoperatively vs. end of follow- } \\
\text { up }\end{array}$ & $0.022 \ddagger$ & $<0.001 \neq$ & & $0.011 \neq$ & $0.003 \neq$ & & $0.002 \ddagger$ & $0.391 \neq$ & \\
\hline
\end{tabular}

up

† One-Way Anova for between-group comparisons; ‡ two tailed paired sample t-Testfor within-group comparisons. IOP Intraocular pressure, PPV Pars plana vitrectomy, SD Standard deviation. 
comparable with the $90 \%$ or more reported in the literature [33]. The reason for failure may have been insufficient gas tamponade, poor patient compliance with prone position, residual epiretinal traction or incomplete removal of posterior hyaloid despite staining, large macular hole of more than $450 \mu \mathrm{m}$ for which ILM Flap technique could have been considered, or no obvious causes $[8,9,34]$.

The mean BCVA improvement of LogMAR 0.25 was identical to the results of further publications after a similar follow-up [35, 36]. Previous publications about FTMH have reported better surgical and functional results in association with better preoperative BCVA, earlier stage of the disease, younger patient age, and shorter duration of the symptoms [37, 38]. In the present study, a significant correlation was measured only between better preoperative BCVA and higher closure rate $(p=0.010)$. The closure rate trended higher in stage 2 than for stage 3 or 4 , but not significantly ( $p=$ 0.189 ). Presumably, the data of these three groups did not allow measuring a significant difference between them considering a quite similar high rate of postoperative closure varying between 96.8 and $90.75 \%$ and possibly an insufficient number of patients. The age of the patients did also not correlate with the closure rate $(p=$ 0.75). Supposedly, the exclusion of patients younger than 50 years hindered the observation of such a difference. Finally, the duration of symptoms was not reliably recorded in this retrospective study so that this parameter could not be considered.

The complications described in the study are consistent with the literature [5]. Only the retinopexy rate of $33.3 \%$ was higher than the published data of $16.1 \%$ [39]. The retrospective character of our study may explain this discrepancy, as we were no longer able to differentiate whether retinopexy was performed because of intraoperative iatrogenic breaks or for already present retinal degenerations. As expected, the number retinopexies required was lower for stage 4 because of the reduced traction of the prior detached vitreous body in this group. Finally, the frequency of postoperative retinal detachment was lower than the $2.4 \%$ documented in the literature [5].

The main limitation of our retrospective study is the short follow-up in the phacovitrectomy group (mean follow-up 16.83 days, range 5-90 days) as well as in the vitrectomy alone group (mean follow-up 17.61 days, range 5-94 days). Actually, we did not intend to monitor the patients at longer intervals and we referred them back to their private ophthalmologist after the confirmation of closure of the FTMH by the mean of OCT. Although loss to record of complications is unlikely because patients are referred to our regional ophthalmology center not only for surgery but also for long- term issues, we cannot completely exclude the possibility that we have missed some patients and may therefore have underestimated the rate of postoperative complication.

In conclusion, the results of the present study showed similar positive results for a phacovitrectomy in phakic eyes compared to a vitrectomy alone in pseudophakic eyes. According to literature, a combined surgery has several advantages over a sequential surgery [30-32]. Therefore, a 23-gauge PPV with phacoemulsification is a viable option to specifically treat phakic patients over 50 years of age with a primary FTMH.

\section{Abbreviations}

BCVA: Best-corrected visual acuity; FTMH: Full-thickness macular hole; IOP: Intraocular pressure; LogMar: Logarithm of the minimum angle of resolution; OCT: Optical coherence tomography

\section{Supplementary Information}

The online version contains supplementary material available at https://doi. org/10.1186/s12886-021-01918-2.

Additional file 1.

\section{Authors' contributions}

Christophe Valmaggia (C.V.), Filip Kostadinov (F.K.), Corina Lang (C.L.), and Josef Guber (J.G.) fulfil the criteria for authorship, namely: substantial contributions to the conception or design of the work (C.V., F.K., J.G.); or the acquisition, analysis, or interpretation of data for the work (C.V., F.K., C.L., J.G.); or the draft and substantial revisions of the work (C.V., F.K., C.L., J.G.); and final approval of the version to be published (C.V., F.K., C.L., J.G.) and agreement to be accountable for all aspects of the work in ensuring that questions related to the accuracy or integrity of any part of the work are appropriately investigated and resolved (C.V., F.K., C.L., J.G.). Christophe Valmaggia (C.V.) is the corresponding author. He ensures that all listed authors have approved the manuscript before submission, including the names and order of authors, and that all authors will receive the submission and all substantive correspondence with editors, as well as the full reviews, verifying that all data, figures, materials, and code, even those developed or provided by other authors, comply with the transparency and reproducibility standards of both the field and journal.

\section{Funding}

The present study is supported neither by a grant nor by a fund. The authors have no proprietary interest.

Availability of data and materials

The datasets used and/or analysed during the current study are available from the corresponding author on reasonable request.

\section{Declarations}

Ethics approval and consent to participate

The study was approved on 30th April 2020 by the local ethics committee (Ethikkommission Ostschweiz, EKOS 20/074; BASEC Nr. 2020 - 01033). The research adhered to the tenets of the Declaration of Helsinki. Written informed consent was obtained from each patient to be included in the study.

\section{Consent for publication}

N/A.

Competing interests

The authors have no conflicts of interest to declare. 


\section{Author details}

'Department of Ophthalmology, Cantonal Hospital St. Gallen, Rorschacher Strasse 95, 9007 St. Gallen, Switzerland. Department of Otolaryngology, Cantonal Hospital Luzern, Spitalstrasse 6000 Luzern 16, Luzern, Switzerland.

\section{Received: 18 October 2020 Accepted: 19 March 202}

\section{Published online: 10 April 2021}

\section{References}

1. Duker JS, Kaiser PK, Binder S, de Smet MD, Gaudric A, Reichel E, et al. The International Vitreomacular Traction Study group classification of vitreomacular adhesion, traction, and macular hole. Ophthalmology. 2013; 120:2611-19.

2. Russo A, Ragusa M, Barbagallo C, Longo A, Avitabile T, Uva MG, et al. miRNAs in the vitreous humor of patients affected by idiopathic epiretinal membrane and macular hole. PLoS One. 2017;12(3):e0174297.

3. Ittarat $\mathrm{M}$, Somkijrungroj $\mathrm{T}$, Chansangpetch $\mathrm{S}$, Pongsachareonnont $\mathrm{P}$. Literature review of surgical treatment in idiopathic full-thickness macular hole. Clin Ophthalmol. 2020;14:2171-83.

4. Forsaa VA, Lindtjørn B, Kvaløy JT, Frøystein T, Krohn J. Epidemiology and morphology of full-thickness macular holes. Acta Ophthalmologica. 2017;96: 397-404.

5. Jackson TL, Donachie PHJ, Sparrow JM, Johnston RL. Database study of vitreoretinal surgery: report 2, macular hole. Ophthalmology. 2013;120: 629-34

6. Evans JR, Schwartz SD, McHugh JD, Thamby-Rajah Y, Hodgson SA, Wormald $\mathrm{RP}$, et al. Systemic risk factors for idiopathic macular holes: a case-control study. Eye. 1998;12:256-9.

7. Parravano M, Giansanti F, Eandi CM, Yap YC, Rizzo S, Virgili G. Vitrectomy for idiopathic macular hole. Cochrane Database Syst Rev. 2015;2015(5): CD009080.

8. Dai $Y$, Dong F, Zhang $X$, Yang Z. Internal limiting membrane transplantation for unclosed and large macular holes. Graefes Arch Clin Exp Ophthalmol. 2016;254:2095-9.

9. Wrzesińska D, Nowomiejska K, Nowakowska D, Toro MD, Bonfiglio V Reibaldi $M$, et al. Secondary vitrectomy with internal limiting membrane plug due to persistent full-thickness macular hole OCT-angiography and microperimetry features: case series. J Ophthalmol. 2020;2020:2650873.

10. Al-Hinai AS. Vitrectomy versus phacovitrectomy. Oman J Ophthalmol. 2019; $12: 71-2$

11. Mercanti A, Renna A. A review of microinvasive combined phacovitrectomy: recent technical advances. Ophthalmol Ther. 2017;6:49-54.

12. Villegas VM, Gold AS, Latiff A, Wildner AC, Ehlies FJ, Murray TG. Phacovitrectomy. . Dev Ophthalmol. 2014;54:102-7.

13. Sizmaz S, Esen E, Isik P. Cam B. Demirca N. Outcome and complications of combined phacoemulsification and 23-gauge pars plana vitrectomy. J Ophthalmol. 2019:2019:7918237.

14. Erçalık NY, Yenerel NM, Sanisoǧlu HA, Kumral ET, Imamoğlu S. Comparison of intra- and postoperative complications of phaco between sequential and combined procedures of 23-gauge vitrectomy and phaco. Saudi Ophthalmol. 2017;31:238-42.

15. Tranos PG, Allan B, Balidis M, Vakalis A, Asteriades S, Anogeianakis G, et al. Comparison of postoperative refractive outcome in eyes undergoing combined phacovitrectomy vs cataract surgery following vitrectomy. Graefes Arch Clin Exp Ophthalmol. 2020;258:987-93.

16. Xiao K, Dong YC, Xiao XG, Liang SZ, Wang J, Qian C, et al. Effect of pars plana vitrectomy with or without cataract surgery in patients with diabetes: a systematic review and meta-analysis. Diabetes Ther. 2019;10:1859-68.

17. Tayyab H, Khan AA, Javaid RMM. Clinical outcome of 23-gauge transconjunctival pars plana vitrectomy: a prospective comparison of phacovitrectomy with only vitrectomy in phakic eyes. Pak J Med Sci. 2017; 33:1123-7.

18. Boiko EV, Churashov SV, Kulikov AN, Maltsev DS. Clear corneal phacovitrectomy with posterior capsulorhexis and IOL implantation in management of selective vitreoretinal cases. J Ophthalmol. 2015;2015: 474072.

19. Pinarci EY, Bayar SA, Sizmaz S, Yesilirmark N, Akkoyun I, Yilmaz G. Anterior segment complications after phacovitrectomy in diabetic and nondiabetic patients. Eur J Ophthalmol. 2013;23:223-9.
20. Sisk RA, Murray TG. Combined phacoemulsification and sutureless 23-gauge pars plana vitrectomy for complex vitreoretinal diseases. Br J Ophthalmol. 2010;94:1028-32.

21. Thompson JT. The role of patient age and intraocular gas use in cataract progression after vitrectomy for macular holes and epiretinal membranes. Am J Ophthalmol. 2004;137:250-7.

22. Huang LL, Levinson DH, Levine JP, Mian U, Tsui I. Optical coherence tomography findings in idiopathic macular holes. J Ophthalmol. 2011;2011: 928205.

23. Kang SW, Ahn K, HAM DI. Types of macular hole closure and their clinical implications. Br J Ophthalmol. 2003:87:1015-9

24. Saito Y, Lewis JM, Park I, Ikuno Y, Hayashi A, Ohji M, et al. Nonvitrectomizing vitreous surgery: a strategy to prevent postoperative nuclear sclerosis. Ophthalmology. 1999;106:1541-5.

25. Reibaldi M, Longo A, Avitabile T, Bonfiglio V, Toro MD, Russo A, et al. Transconjunctival nonvitrectomizing vitreous surgery versus 25-gauge vitrectomy in patients with epiretinal membrane: a prospective randomized study. Retina. 2015;35:873-9.

26. Holekamp NM, Shui YB, Beebe DC. Vitrectomy surgery increases oxygen exposure to the lens: a possible mechanism for nuclear cataract formation Am J Ophthalmol. 2005;139:302-10.

27. Elhousseini Z, Lee E, Williamson TH. Incidence of lens touch during pars plana vitrectomy and outcomes from subsequent cataract surgery. Retina. 2016;36:825-9.

28. Cheng L, Azen SP, El-Bradey MH, Scholz BM, Chaidhawangul S, Toyoguchi $M$, et al. Duration of vitrectomy and postoperative cataract in the vitrectomy for macular hole study. Am J Ophthalmol. 2001;132:881-7.

29. Chang MA, Parides MK, Chang S, Braunstein RE. Outcome of phacoemulsification after pars plana vitrectomy. Ophthalmology. 2002;109: 948-54.

30. Rogers S, Madhusudhana KC, Kang HK, Luff AJ, Canning CR, Newsom SB. Combined phacovitrectomy for macular hole: long-term results. Ophthalmic Surg Lasers Imaging. 2007:38:452-6.

31. Lee JY, Kim KH, Shin KH, Han DH, Lee DY, Nam DH. Comparison of intraoperative complications of phacoemulsification between sequential and combined procedures of pars plana vitrectomy and cataract surgery. Retina. 2012:32:2026-33.

32. Seider MI, Lahey M, Fellenbaum PS. Cost of phacovitrectomy versus vitrectomy and sequential phacoemulsification. Retina. 2014;34:1112-5.

33. Margherio RR, Margherio AR, Williams GA, Chow DR, Banach MJ. Effect of perifoveal tissue dissection in the management of acute idiopathic fullthickness macular holes. Arch Ophthalmol. 2000;118:495-8.

34. Bottoni F, Parrulli S, Mete M, D’Agostino I, Cereda M, Cigada M, et al. Large idiopathic macular hole surgery: remodelling of outer retinal layers after traditional internal limiting membrane peeling or inverted flap technique. Ophthalmologica. 2020:243:334-41.

35. Kim SH, Kim HK, Yang JY, Lee SC, Kim SS. Visual recovery after macular hole surgery and related prognostic factors. Kor J Ophthalmol. 2018:32:140-6.

36. Itoh Y, Inoue M., Rii T, Hiraoka T, Hirakata A. Correlation between length of foveal cone outer segment tips line defect and visual acuity after macular hole closure. Ophthalmology. 2012;119:1438-46.

37. Reibaldi M, Avitabile T, Longo A, Uva MG, Bonfiglio V, Russo A, et al. Correlation of preoperative retinal pigment epithelium status with foveal microstructure in repaired macular holes. Ophthalmologica. 2014;232:194-9.

38. Fallico M, Jackson TL, Chronopoulos A, Hattenbach LO, Longo A, Bonfiglio $\checkmark$, et al. Factors predicting normal visual acuity following anatomically successful macular hole surgery. Acta Ophthalmol. 2020. 10.1111/aos.14575.

39. Dogramaci M, Lee EJK, Williamson TH. The incidence and the risk factors for iatrogenic retinal breaks during pars plana vitrectomy. Eye. 2012;26:718-22.

\section{Publisher's Note}

Springer Nature remains neutral with regard to jurisdictional claims in published maps and institutional affiliations. 